\title{
Variability in Isolated Convective Activity between Louisville, Kentucky, and Nearby Rural Locations
}

\author{
JASON NAYLOR ${ }^{\mathrm{a}}$ AND AARON D. KENNEDY ${ }^{\mathrm{b}}$ \\ ${ }^{a}$ Department of Geography and Geosciences, University of Louisville, Louisville, Kentucky \\ ${ }^{\mathrm{b}}$ Department of Atmospheric Sciences, University of North Dakota, Grand Forks, North Dakota
}

(Manuscript received 14 July 2020, in final form 12 February 2021)

\begin{abstract}
This study analyzes the frequency of strong, isolated convective cells in the vicinity of Louisville, Kentucky. Data from the Severe Weather Data Inventory are used to compare the frequency of convective activity over Louisville with the observed frequency at nearby rural locations from 2003 to 2019. The results show that Louisville experiences significantly more isolated convective activity than do the rural locations. The difference in convective activity between Louisville and the rural locations is strongest during summer, with peak differences occurring between May and August. Relative to the rural locations, Louisville experiences more isolated convective activity in the afternoon and early evening but less activity after midnight and into the early morning. Isolated convective events over Louisville are most likely during quiescent synoptic conditions, whereas rural events are more likely during active synoptic patterns. To determine whether these differences can be attributed primarily to urban effects, two additional cities are shown for comparison-Nashville, Tennessee, and Cincinnati, Ohio. Both Nashville and Cincinnati experience more isolated convective activity than all five of their nearby rural comparison areas, but the results for both are statistically significant at four of the five rural locations. In addition, the analysis of Cincinnati includes a sixth comparison site that overlaps the urbanized area of Columbus, Ohio. For that location, differences in convective activity are not statistically significant.
\end{abstract}

KEYWORDS: Deep convection; Radars/radar observations; Atmosphere-land interaction; Local effects; Urban meteorology

\section{Introduction}

Numerous studies have found that precipitation patterns can be influenced by large urban areas. One of the first projects to study this effect was the Metropolitan Meteorological Experiment (METROMEX; e.g., Changnon et al. 1971; Huff and Changnon 1973; Changnon et al. 1977), which found evidence of precipitation enhancement downwind of Saint Louis, Missouri. Since METROMEX, numerous subsequent studies have focused on other metropolitan areas. There is general agreement among these studies that urban areas can modify precipitation patterns, but results have differed regarding the type of modification, magnitude of the signal, and underlying physical mechanism(s) responsible for alterations to precipitation distributions around these areas.

While Saint Louis was the primary focus of many pioneering studies on urban-induced precipitation variations, Atlanta, Georgia, has been the most frequent focus of modern studies (e.g., Dixon and Mote 2003; Mote et al. 2007; Shem and Shepherd 2009; Bentley et al. 2012; Haberlie et al. 2015). Although these studies have shown that Atlanta experiences more warm-season convective events than surrounding rural regions, the results from one city should not necessarily be

Corresponding author: Jason Naylor, jason.naylor@louisville.edu

Earth Interactions is published jointly by the American Meteorological Society, the American Geophysical Union, and the Association of American Geographers. extrapolated to other large cities. For example, Huff and Changnon (1973) found evidence of urban-induced precipitation enhancement in six of eight cities studied, but there was substantial variability regarding magnitude, location, and even timing of the enhancement among those cities. Shepherd et al. (2002) found evidence of downwind precipitation enhancement in five different U.S. cities; however, the magnitude of those anomalies (relative to precipitation amounts in the upwind area) varied from $15 \%$ to $51 \%$. Furthermore, Ganeshan et al. (2013) determined that the urban influence on precipitation patterns varies by geography, with inland cities experiencing an increase in nocturnal convection and coastal cities experiencing an increase in afternoon convection. Recently, Liu and Niyogi (2019) performed a meta-analysis of previous studies on urban-induced precipitation modification. They found that the most commonly reported signal was precipitation enhancement $20-50 \mathrm{~km}$ downwind of the urban center.

There is also some disagreement as to the exact physical mechanism responsible for urban-induced precipitation changes. While it has been suggested that surface roughness gradients (e.g., Hjelmfelt 1982; Thielen et al. 2000), urban aerosols (e.g., Jin et al. 2005; van den Heever and Cotton 2007; Stallins et al. 2013; Ochoa et al. 2015), and urban moisture availability (e.g., Braham et al. 1981) may play a role, numerous studies are in general agreement that the urban heat island (UHI) is responsible in some way (e.g., Bornstein and Lin 2000; Dixon and Mote 2003; Rozoff et al. 2003). These studies have found evidence that UHIs produce convergence zones that can initiate new convection.

Most previous work has focused on all forms of convective activity, with some studies including cells that reach a maximum 

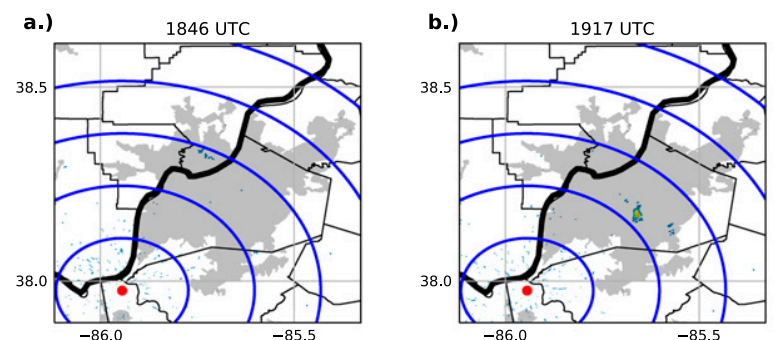

c.)

1936 UTC

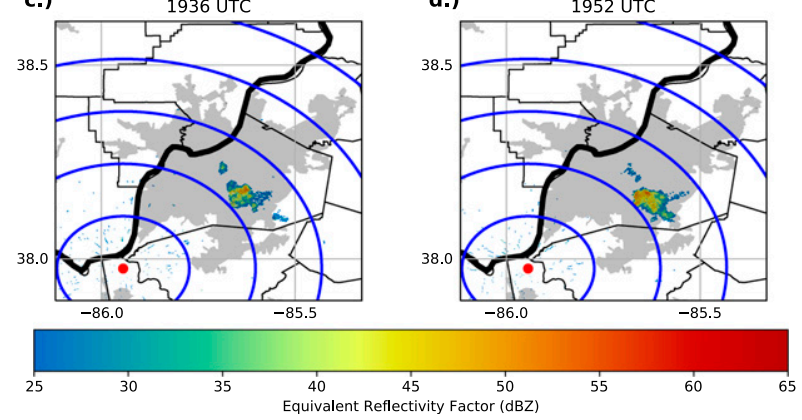

FIG. 1. Radar observations of a convective initiation event over Louisville from $10 \mathrm{Jul} 2019$. Displayed is base tilt $\left(0.5^{\circ}\right)$ equivalent reflectivity factor from the KLVX WSR-88D for (a) 1846, (b) 1917, (c) 1936, and (d) 1952 UTC. Blue lines are range rings drawn in intervals of $15 \mathrm{~km}$, and the red dot is the location of KLVX. Urban areas as identified by the U.S. Census Bureau are shaded in gray. The thick black line is the Kentucy-Indiana border (Ohio River), and the thinner black lines represent county boundaries.

reflectivity as low as $40 \mathrm{~dB} Z$ (e.g., Haberlie et al. 2015). Several recent studies have focused specifically on the impact urban areas may have on strong, deep convection capable of producing severe weather. Naylor and Sexton (2018) found that storm-based National Weather Service warnings and the frequency of convective cells with a reflectivity of $50 \mathrm{~dB} Z$ or more are maximized on the downwind side of several large cities. Reames and Stensrud (2018) performed Weather Research and Forecasting (WRF) Model simulations of a supercell and found that the strength of low-level rotation, as well as the track of the near-surface mesocyclone, can be impacted by the presence of a large city.

Results from METROMEX suggest that urban areas are more likely to enhance existing precipitation systems than to initiate new convective cells (e.g., Huff and Changnon 1973). A similar conclusion was reached by Shem and Shepherd (2009) in their analysis of two separate convective events over Atlanta, Georgia. Niyogi et al. (2011) also found observational evidence of storms changing structure when interacting with a city. Using a large radar-based climatology of convective events over a 10-yr period, they found that thunderstorms approaching Indianapolis, Indiana, were more likely to change structure when passing over the city compared to thunderstorms passing over nearby rural regions. However, other studies have found strong evidence of urban-induced convective initiation (e.g., Bornstein and Lin 2000; Craig and Bornstein 2002; Dixon and Mote 2003; Haberlie et al. 2015).

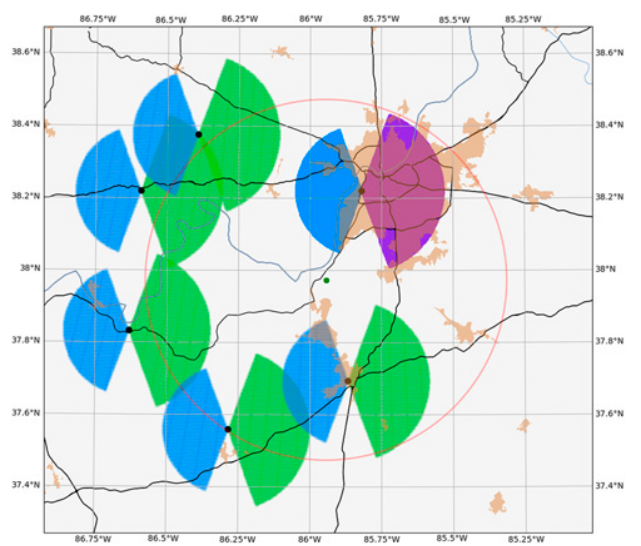

FIG. 2. Map showing the relative positions of Louisville, the KLVX WSR-88D (green dot), and the five RPs used for comparison. The urban focus area over Louisville is indicated in purple, and the control area is in blue. For each RP, the focus area is in green and the control area is in blue. The red ring represents a circle centered on the KLVX radar to indicate the relative radar distance of each of the focus areas. The U.S. Census Bureau urban areas are shaded in orange. The black lines are major area roads, and the blue line is the Ohio River.

These initiation events are most often associated with warm humid air masses and synoptically benign conditions during the peak in summer. As pointed out by Haberlie et al. (2015), studies investigating the climatology of urban-induced convection are much less common in the literature than more general climatological studies of thunderstorm occurrence around large cities.

The goal of this study is to further investigate the impact of large urban areas on convective initiation and the occurrence of isolated deep convective storms capable of producing hazards such as flash floods, damaging winds, and hail. The primary focus area is Louisville, Kentucky. Previous research has shown that Louisville has one of the strongest UHIs in the United States (Debbage and Shepherd 2015). Since processes associated with UHIs are believed to be related to precipitation modification, it is possible that Louisville may have a detectable influence on area precipitation. An example of a summertime convective initiation event over Louisville on 10 July 2019 is shown in Fig. 1. This cell developed during the afternoon on the eastern side of the city with no other convective activity in the vicinity. This cell remained relatively stationary as it grew in size over a period of approximately $40-50 \mathrm{~min}$ and reached a maximum radar reflectivity value $\geq$ $50 \mathrm{dBZ}$. After the storm propagated out of the city, it dissipated (not shown). The main goal of this study is to determine if events such as this are more common over Louisville than nearby rural areas.

This study differs from previous studies of urban-induced and urban-enhanced convection in several ways. First, we focus only on "strong" convective cells, with convective strength based on observed radar reflectivity. Second, many previous studies have focused only on warm-season convection, while others have gone a step further to restrict their search to warm- 
TABLE 1. Summary of convective activity at Louisville and each of the nearby RPs. The latitude and longitude values represent the origin point of the focus and control regions. The $p$-value column represents the one-sided value calculated from permutation testing of $\overline{\mathrm{urb}} / \overline{\mathrm{rur}}$. The Wilcoxon $p$-value column represents the $p$ value from a Wilcoxon signed-rank test. Statistically significant differences (as determined by $p$ value) at the $95 \%$ confidence level or greater are italicized in boldface type.

\begin{tabular}{lccccccc}
\hline \hline Location & Lat & Lon & Total events & Avg & Median & $p$ value & Wilcoxon $p$ value \\
\hline Louisville & 38.2211 & -85.8211 & 116 & 6.8 & 7 & & $\mathbf{0 . 0 0 6}$ \\
RP1 & 38.2195 & -86.5935 & 62 & 3.6 & 3 & $\boldsymbol{0 . 0 0 0 0 5}$ & $\boldsymbol{0 . 0 0 6}$ \\
RP2 & 37.8332 & -86.6332 & 77 & 4.5 & 5 & $\boldsymbol{0 . 0 0 6}$ & $\boldsymbol{0 . 0 0 2}$ \\
RP3 & 37.5589 & -86.2859 & 78 & 4.6 & 5 & $\boldsymbol{0 . 0 0 4}$ & $\mathbf{0 . 0 2}$ \\
RP4 & 37.5185 & -85.7295 & 87 & 5.1 & 5 & $\boldsymbol{0 . 0 3}$ & $\mathbf{0 . 0 0 7}$ \\
RP5 & 37.7071 & -85.4441 & 74 & 4.3 & 5 & $\boldsymbol{0 . 0 0 3}$ & \\
\hline
\end{tabular}

season events that occur under a specific type of air mass (e.g., Dixon and Mote 2003; Mote et al. 2007; Bentley et al. 2012; Haberlie et al. 2015). This study has no such restrictions. Any convective event that meets the specified criteria will be considered, regardless of the season in which it occurred or the synoptic conditions associated with it. The focus of this current study is the initiation of new cells over the urban area itself. While many previous studies have found an increase in precipitation downwind of large cities, our goal is to examine the occurrence of strong, discrete convective activity over a large city.

\section{Method}

\section{a. Identification of urban and rural cases}

Data from the Severe Weather Data Inventory (SWDI; Ansari et al. 2009) are used to create a radar-based climatology of convective activity around a specified point from January 2003 through December 2019. The SWDI dataset includes the Level III "Storm Structure" product from National Weather Service WSR-88D instruments, which contains information for identified cells such as time, latitude/longitude, maximum reflectivity, vertically integrated liquid water content, and cloud

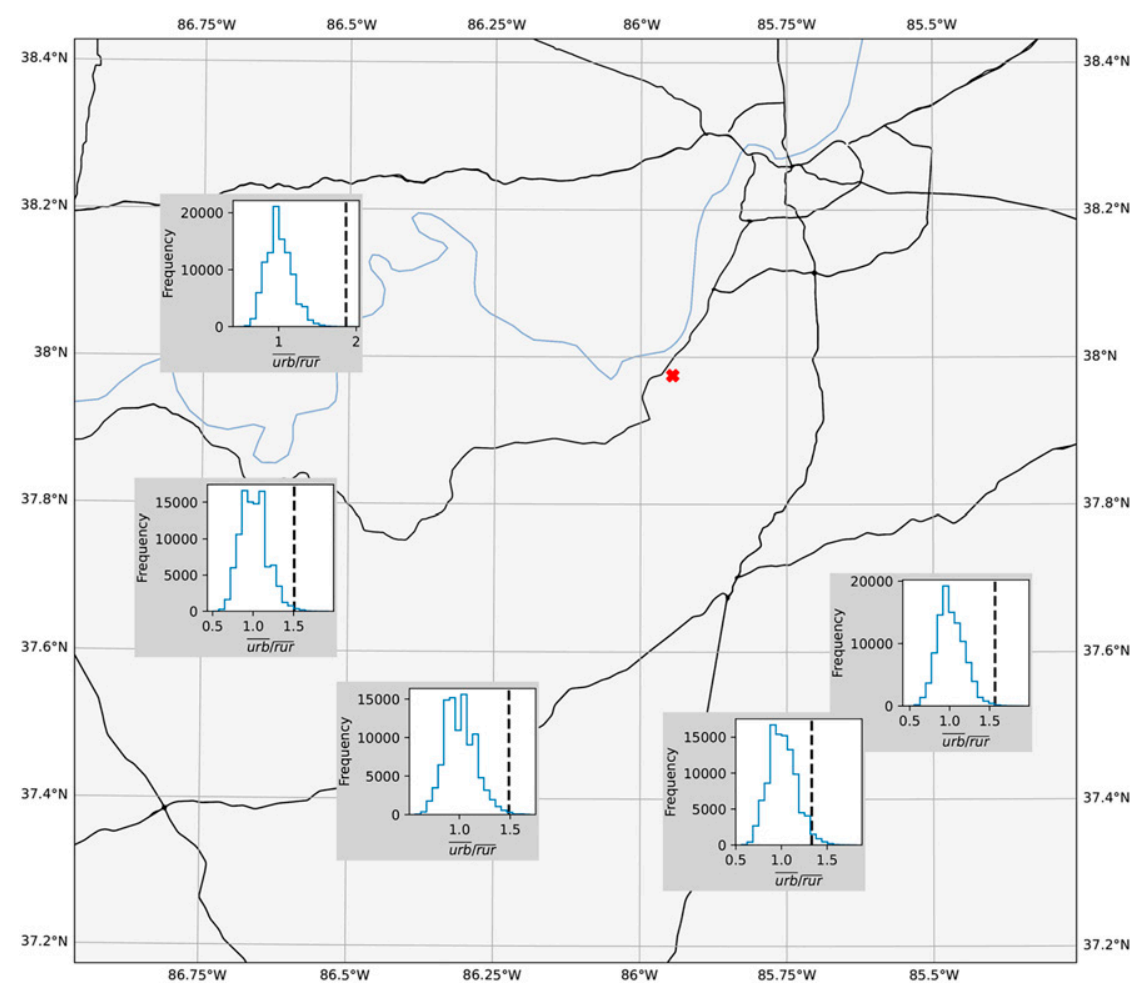

FIG. 3. Distributions of the mean number of urban events per year divided by the mean number of rural events per year at each RP. Distributions are based on permutation testing of 100000 samples. The vertical dotted black line indicates the observed ratio of the mean values at each RP. The red $x$ represents the location of the KLVX radar. Black and blue lines are the same as in Fig. 2. 


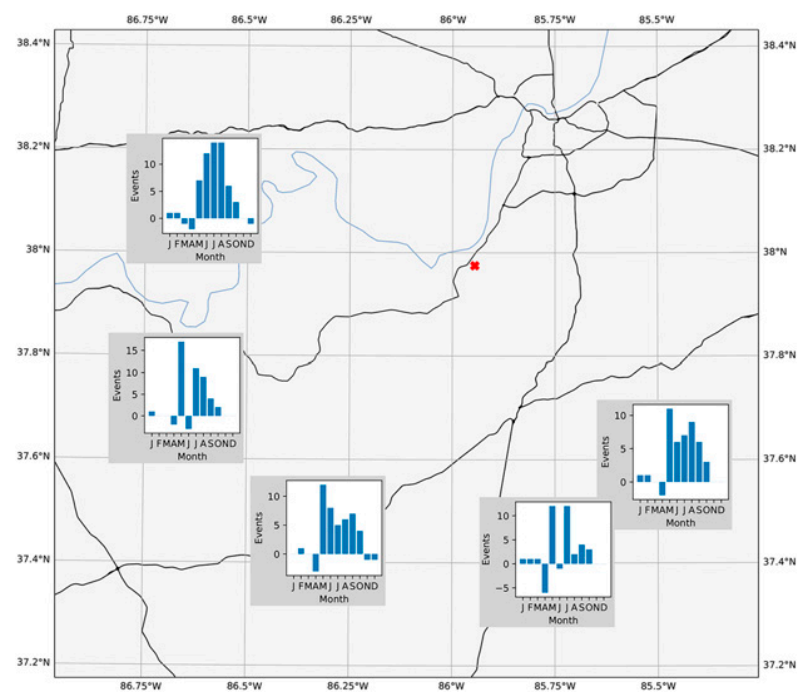

FIG. 4. Observed monthly differences in convective activity between Louisville and each RP. Lines and markers are the same as in Fig. 3.

depth. These data have a temporal resolution of $5 \mathrm{~min}$. For an analysis of Louisville and the surrounding area, data from the KLVX radar at Fort Knox, Kentucky, are used.

To identify instances of strong, isolated convective activity over Louisville, we create a "cone of influence" relative to a particular location using a process described in Naylor and Sexton (2018). This creates fanlike areas emanating from the reference location in either direction (Fig. 2). Similar approaches have been adopted by many previous studies involving urban precipitation anomalies (e.g., Huff and Changnon 1973; Shepherd and Burian 2003). The "focus" area over Louisville (purple portion in Fig. 2) extends $25 \mathrm{~km}$ eastward from the point of origin and the "control" area (blue portion of Fig. 2) extends $20 \mathrm{~km}$ westward from the point of origin. Since convection is discrete by its very nature, initiation of convection over a particular point on the surface does not necessarily mean that the properties of the underlying surface substantially impacted that development. To determine if isolated convective activity over Louisville is more common in comparison with nearby areas, the method described above was repeated at five rural points (RPs). At each of these selected RPs, focus and control areas were defined (centered on the latitude and longitude of the RP) and the SWDI dataset was searched for instances of strong convection in the focus area but not in the control area. Because cell detection and radar reflectivity are strongly influenced by distance from the radar, the RPs were chosen at points located at a similar distance from the KLVX radar as Louisville (Fig. 2). The lowest possible radar beam height (assuming $0.5^{\circ}$ elevation angle) within the various focus regions shown in Fig. 2 ranges from approximately 300 to $900 \mathrm{~m}$.

The reference location and radial extent were chosen such that the majority of Louisville is contained within the focus area. The geometry of the focus region is intended to minimize nonurban land use within the shape. For example, if a

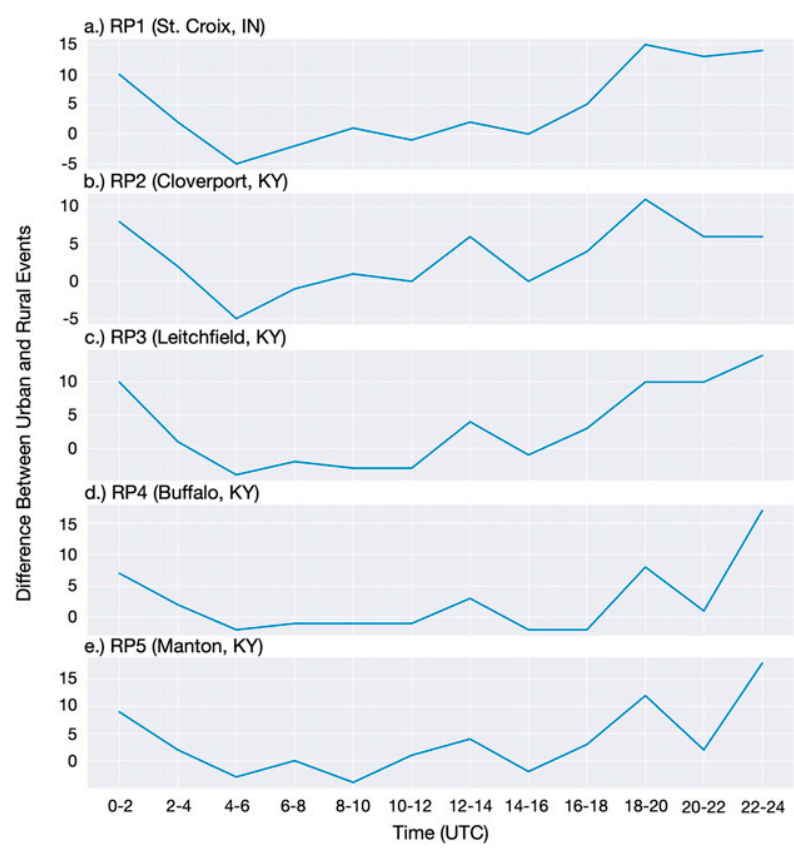

FIG. 5. Differences in convective activity between Louisville and each RP as a function of time of day.

semicircle were chosen instead of a cone, the focus area would extend to areas $20 \mathrm{~km}$ directly north and south of the radial center. This would include a heavily forested area near Fort Knox and rural areas in southern Indiana. To be considered a strong isolated event, convection exceeding a predefined reflectivity threshold must be identified within the focus area with no detections of $30 \mathrm{dBZ}$ or greater in the control area during a moving 3-h window. The radial extent of each cone was determined by trial and error. The purpose of the control area is to identify and remove events with 1 ) existing cells that were advected over Louisville due to the prevailing winds and 2) widespread convective initiation over a large area.

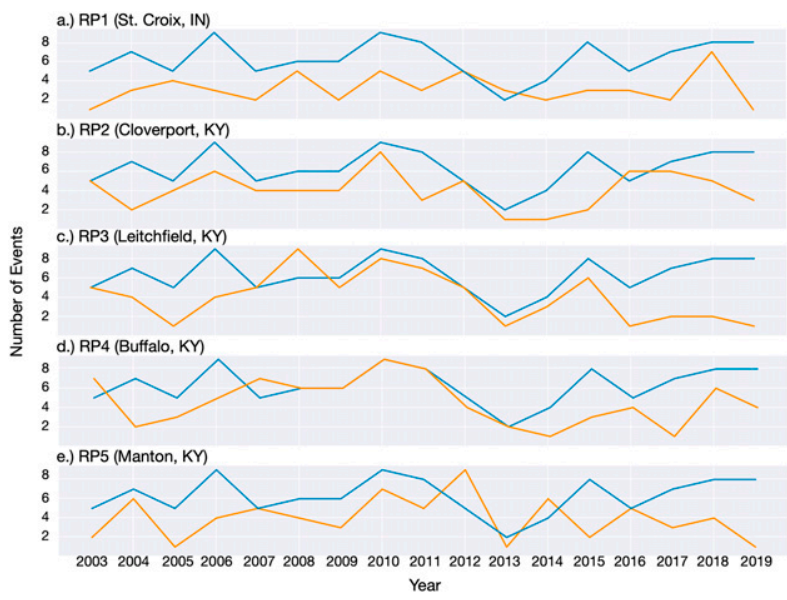

FIG. 6. Time series of convective events per year at Louisville (the blue line, repeated in each panel) and the designated RPs (orange lines). 
a.)

b.)
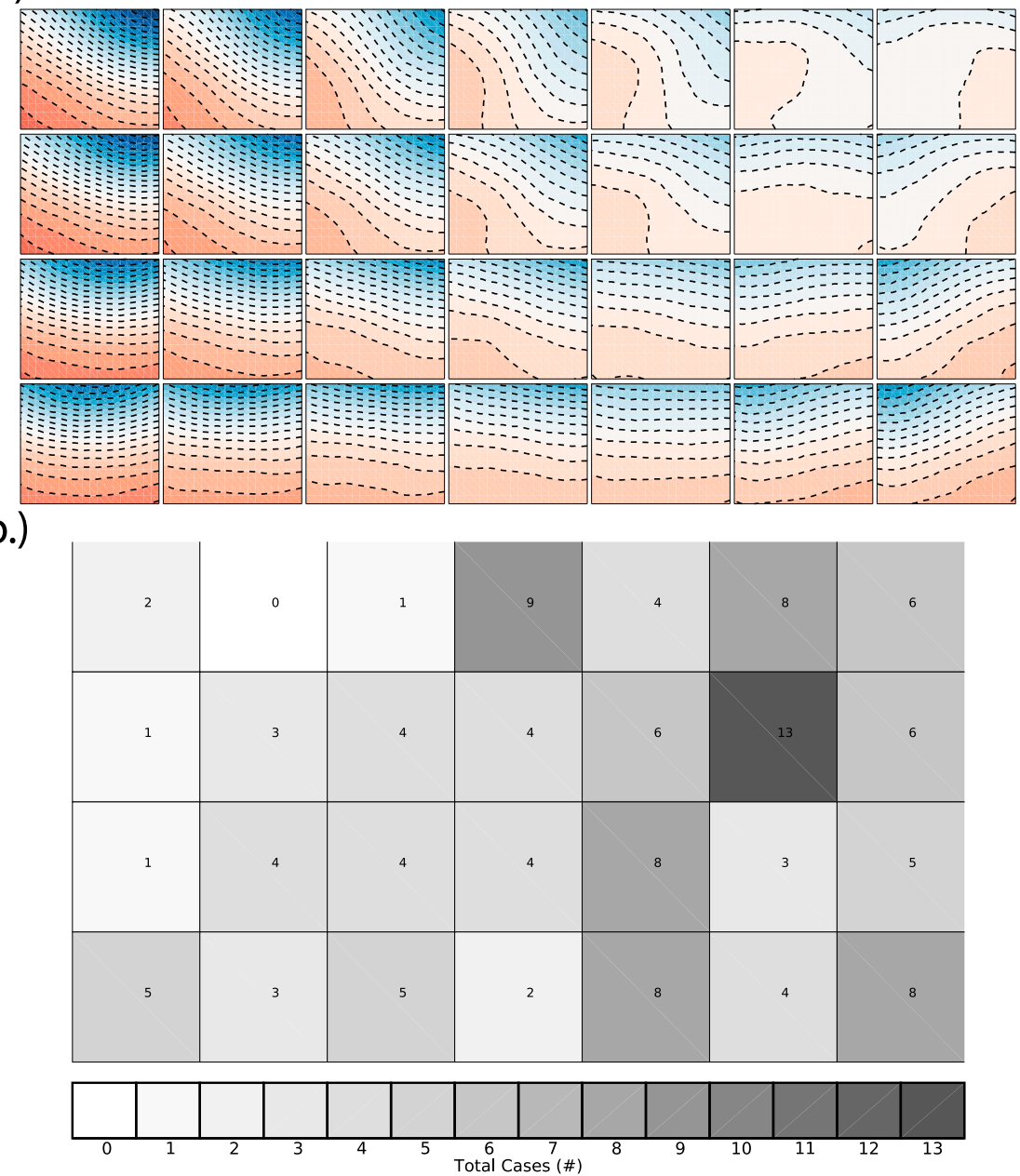

FIG. 7. (a) The 500 -hPa height anomalies for the $7 \times 4$, 28-class SOM. Reddish and bluish colors represent positive and negative anomalies, respectively. (b) Total case count for the SOM. The total number of cases within the SOM is 131 .

Case selection was automated using a Python script to search the SWDI dataset for events that met the defined criteria. Various reflectivity thresholds were tested and identified cases were manually checked for consistency. It was found that lower reflectivity thresholds (such as $50 \mathrm{dBZ}$ ) produced too many "false alarms" - cases in which relatively weak cells met the maximum reflectivity threshold for just a single scan. Choosing too large of a threshold limited the number of available cases. Thus, $55 \mathrm{~dB} Z$ was chosen as an acceptable threshold to identify "strong" convection. This threshold value yielded a reasonable number of events (116) while also limiting the number of weaker convective events detected by the data-mining code.

Detected cases are a combination of discrete convective initiation as well as the enhancement of existing, weak clouds. For example, it is possible for a weak, developing convective cell with a reflectivity of less than $30 \mathrm{dBZ}$ to move from the control region and then intensify to greater than $55 \mathrm{~dB} Z$ in the focus region. ${ }^{1}$ New cells may also be initiated directly in the focus region without any prior weak cell detections in the control region. A manual inspection of cases identified by the detection script revealed that the majority of cases involve the initiation of a single cell near Louisville with no other convection within $30 \mathrm{~km}$ of the city-similar to the event depicted in Fig. 1. There are also several cases where an existing convective system approaches Louisville without passing into the control area, and new cells initiate within the defined focus region. It is also

\footnotetext{
${ }^{1}$ Mecikalski and Bedka (2006) define convective initiation as having occurred when reflectivity of $35 \mathrm{dBZ}$ or greater is detected by a WSR-88D. By that criterion, weak cells moving from the control area into the focus area before intensifying to $35 \mathrm{dBZ}$ or more would be categorized as having initiated in the focus area.
} 
a.)
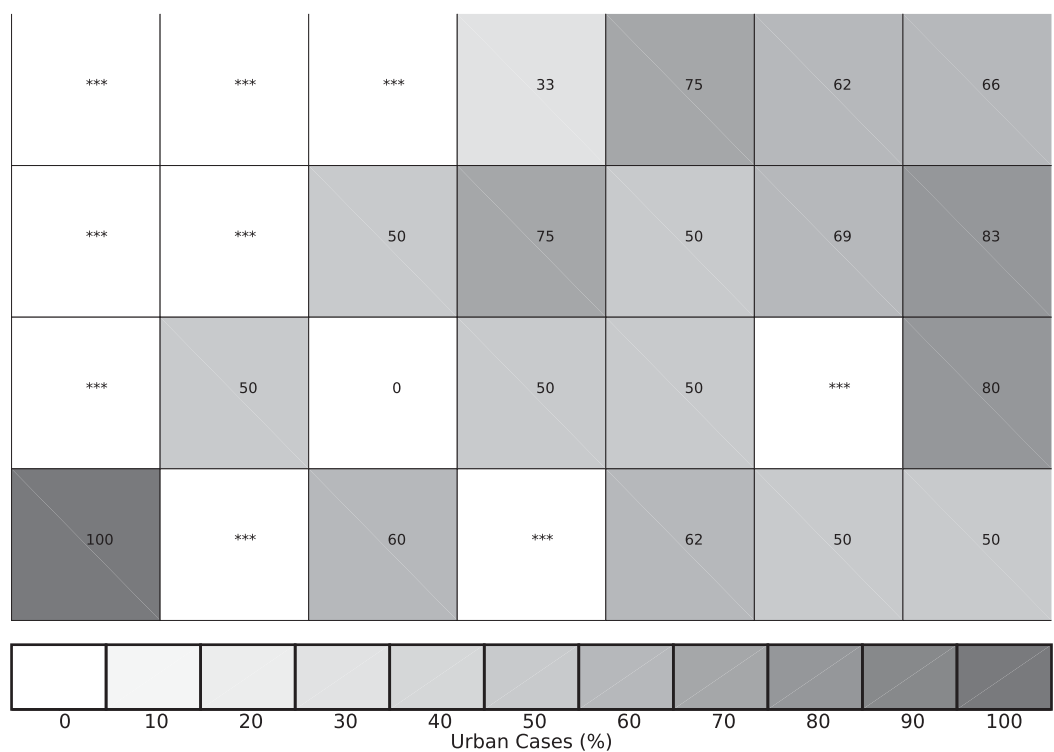

b.)

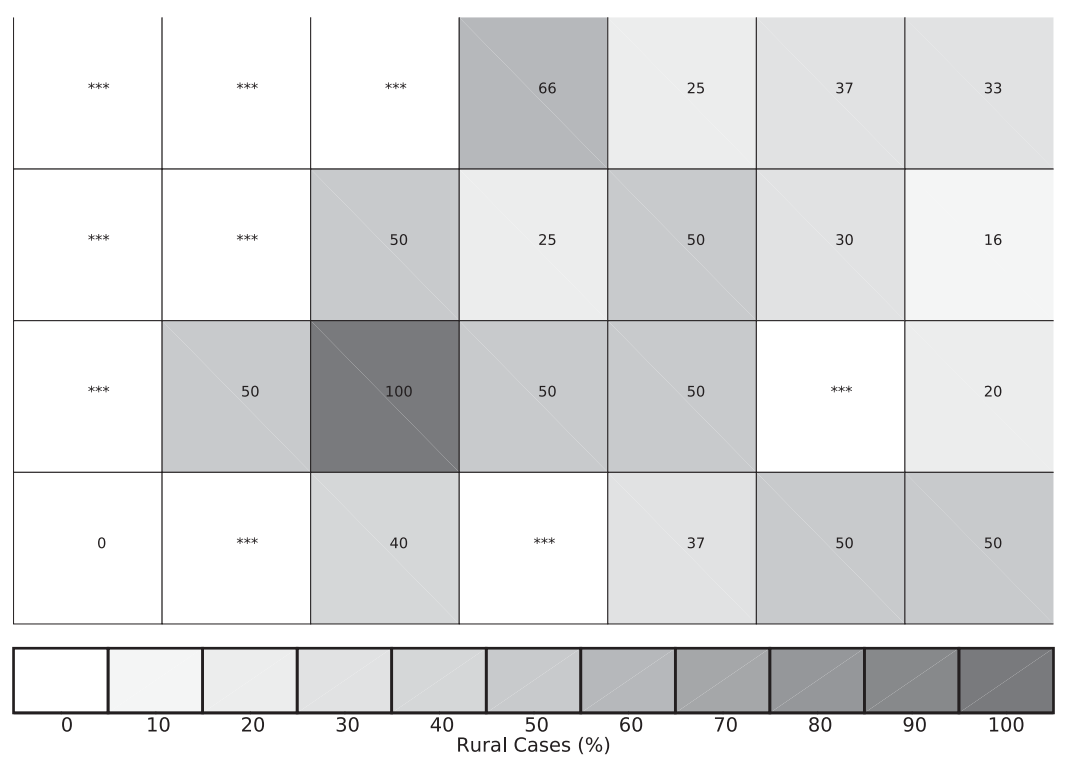

FIG. 8. Fraction of (a) urban and (b) rural cases for the 28-class SOM shown in Fig. 7. Nodes with three or fewer cases are masked and are denoted with three asterisks.

possible that a strong existing cell that developed well outside of Louisville could pass through one of the "gaps" between the focus and control regions, travel into the focus region and be labeled as an initiation event by the analysis code. A manual investigation revealed that this scenario was relatively rare and accounts for less than $10 \%$ of the total number of detections.

Statistical analysis was performed to determine if significant differences in convective activity exist between Louisville and the RPs. Statistical significance was investigated using permutation testing of yearly convective counts at each location (e.g., Wilks 2006). The test statistic used for the resampling method was the ratio of yearly mean isolated convective cases between the urban location and RPs (herein, $\overline{\mathrm{urb}} / \overline{\mathrm{rur}}$ ). For each RP, 100000 randomly generated samples of the observed yearly convective urban and rural counts were created. For each sample, $\overline{\text { urb}} / \overline{\text { rur }}$ was calculated and the distribution of $\overline{\mathrm{urb}} / \overline{\mathrm{rur}}$ was compared with the observed value. The $p$ value was determined by the fraction of simulated $\overline{\mathrm{urb}} / \overline{\mathrm{rur}}$ values that exceeded the observed value. For comparison to the permutation method, the $p$ value was also calculated using the commonly used Wilcoxon signed-rank test for each location (Wilcoxon 1945).

\section{b. Synoptic environments of cases}

To investigate how cases are related to synoptic environments, a competitive neural network known as the self-organizing map 

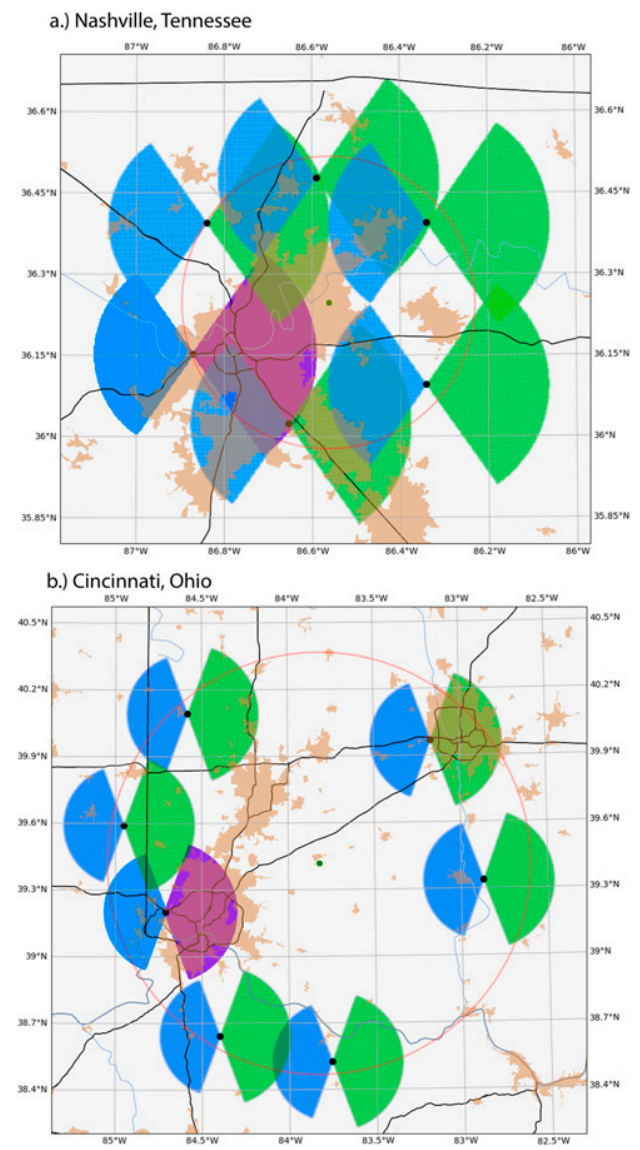

FIG. 9. As in Fig. 2, but for (a) Nashville and (b) Cincinnati. The green dot in (a) indicates the KOHX radar, and the green dot in (b) indicates the KILN radar. In (b), a sixth comparison site is included (located at $39.9697^{\circ},-83.1691^{\circ}$ ) that overlaps the urbanized area of Columbus.

(SOM; Kohonen 1989) was used to objectively classify 500-hPa geopotential height patterns from the North American Regional Reanalysis (NARR; Mesinger et al. 2006). For the sake of brevity, the reader is referred to Kennedy et al. (2016), Kennedy et al. (2019), and Wang et al. (2019) for details on the merits of SOMs. The training process for this study is most similar to Wang et al. (2019). Differences with this study include geographical area, the selection of training samples, and the use of only $500-\mathrm{hPa}$ heights (vs combinations of atmospheric variables). In the latter case, additional variables did not improve discrimination of urban versus rural cases.

SOMs were created for the summer (June-August) from 0000 UTC NARR height patterns from 2003 to 2019. This subset of time (vs the entire season) allowed us to emphasize variability between quiescent and synoptically active periods and also highlights a period when the greatest difference in cases was observed (see section 3a). Inclusion of patterns from other months skewed results to more active patterns and led to larger classification errors. In total, 17 years of summer seasons provided 1564 training samples. Like these prior studies, NARR was averaged to $1^{\circ} \times 1^{\circ}$ grid for a $15^{\circ}$ latitude $\times$ $19^{\circ}$ longitude region but centered on Louisville. The height field was calculated as an anomaly from the domain average to prevent biases due to seasonally dependent thermal thickness (Kennedy et al. 2016). Various size SOMs were created, but the best balance between number of convective cases and variability expressed by the SOM occurred for a 28 -class, $7 \times 4$ map. Urban and rural cases were then classified to the SOM using the minimum Euclidean distance for the NARR 3-h time step closest in time.

\section{Results}

\section{a. Convective initiation near Louisville}

Using the criteria outlined above, 116 cases were identified over Louisville during the period from 2003 to 2019 (Table 1). The total number of events at the RPs ranges from 62 (RP1) to 87 (RP4). The average (6.8) and median (7.0) values are also greater than at any of the RPs. At RP1, the median is less than half of the Louisville value. To determine the statistical significance of these results, permutation testing was completed using 100000 randomly generated samples. Figure 3 shows the distribution of the test statistic, $\overline{\mathrm{urb}} / \overline{\mathrm{rur}}$, at RPs $1-5$. At each location, the observed value of $\overline{\mathrm{urb}} / \overline{\mathrm{rur}}$ is located at the tail end of the randomly generated values. The one-sided $p$ values indicate that the observed differences are statistically significant at the $95 \%$ confidence level (or greater) for each of the five RPs (Table 1).

Convective events were grouped by month and the difference in monthly count between Louisville and each RP was calculated (Fig. 4). As expected, the largest differences in urban and rural counts occur during meteorological summer, with May through August typically being the months of peak difference. Although convective activity is less common at all locations during the cool season, Louisville appears to have less convective activity than several of the RPs during the winter and early spring. A comparison between the timing of convective events over Louisville and the RPs is shown in Fig. 5. Differences are largest between 1800 and 0200 UTC, indicating that Louisville experiences more convective activity (relative to the surrounding RPs) beginning in the afternoon and ending before midnight local time. This time frame is similar to that identified by Haberlie et al. (2015) for convective initiation around Atlanta but slightly longer than the time period of maximum urban-associated rainfall over Atlanta identified by McLeod et al. (2017). At four of the five RPs shown in Fig. 5, the difference is largest between 1800 and 0000 UTC. However, Fig. 5 also shows that each RP experiences more convective activity overnight and during the morning hours relative to Louisville. This difference peaks sometime between 0400 and 1000 UTC.

Figure 6 shows time series of urban-rural convective activity during each year of the study period. The most convective events over Louisville occurred in 2006 and 2010. Overall, there is no detectable upward or downward trend in the number of events per year. For the RPs, there is some shared signal, but not always. For example, all locations experienced a relatively high amount of convective activity in 2010 and a 
TABLE 2. As in Table 1, but for Cincinnati and Nashville.

\begin{tabular}{|c|c|c|c|c|c|c|c|}
\hline Location & Lat & Lon & Total events & Avg & Median & $p$ value & Wilcoxon $p$ value \\
\hline Nashville & 36.214 & -86.8215 & 175 & 10 & 10 & & \\
\hline RP1 & 36.4779 & -86.5905 & 143 & 8.4 & 8 & 0.045 & 0.04 \\
\hline RP2 & 36.3945 & -86.84 & 146 & 8.6 & 9 & 0.056 & 0.054 \\
\hline RP3 & 36.0201 & -86.6546 & 136 & 8 & 8 & 0.017 & 0.03 \\
\hline RP4 & 36.0956 & -86.3415 & 145 & 8.5 & 8 & 0.047 & 0.08 \\
\hline RP5 & 36.3945 & -86.3394 & 132 & 7.7 & 7 & 0.012 & 0.02 \\
\hline Cincinnati & 39.2031 & -84.712 & 104 & 6.1 & 6 & & \\
\hline RP1 & 38.6428 & -84.3979 & 70 & 4.1 & 4 & 0.008 & 0.012 \\
\hline RP2 & 39.5923 & -84.9523 & 58 & 3.4 & 3 & 0.001 & 0.007 \\
\hline RP3 & 40.0927 & -84.5832 & 76 & 4.5 & 4 & 0.03 & 0.04 \\
\hline RP4 & 39.3382 & -82.8723 & 82 & 4.8 & 5 & 0.054 & 0.08 \\
\hline RP5 & 38.5272 & -83.7555 & 70 & 4.1 & 4 & 0.008 & 0.02 \\
\hline CBS & 39.9697 & -83.1691 & 89 & 5.2 & 4 & 0.22 & 0.23 \\
\hline
\end{tabular}

lower amount in 2013. Similar patterns were also evident for Louisville during these years. At each RP, there is at least one year where convective activity was the same or greater than Louisville. RP4 has the greatest number of years when this occurs (7), while RP1 has the least (2).

\section{b. Partitioning of events by 500-hPa height patterns}

The summer months of June-August were used to classify climatological 500-hPa height patterns surrounding Louisville from 2003 to 2019 (Fig. 7). The SOM captures variability

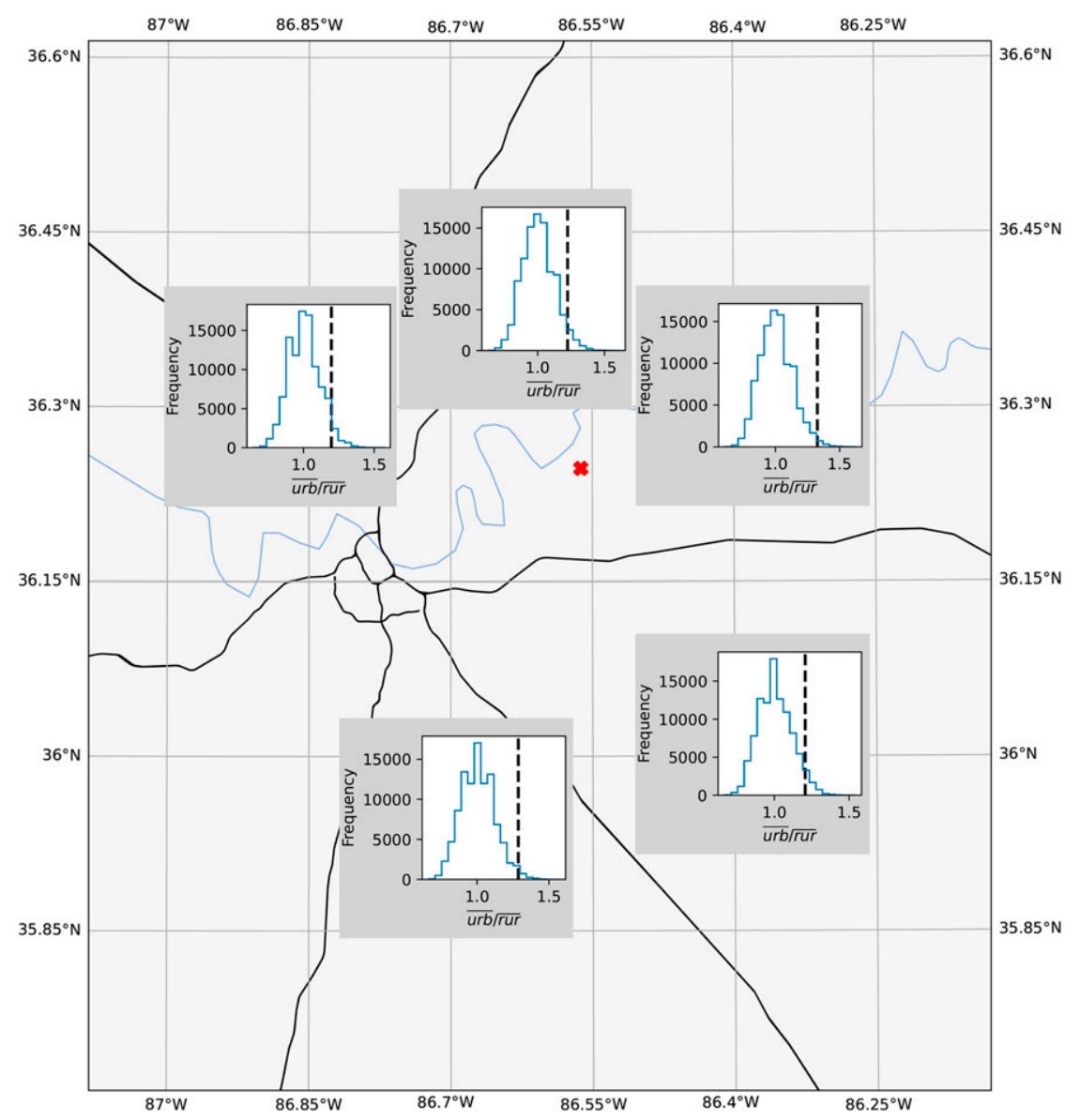

FIG. 10. As in Fig. 3, but for Nashville. The red $x$ represents the KOHX radar. 


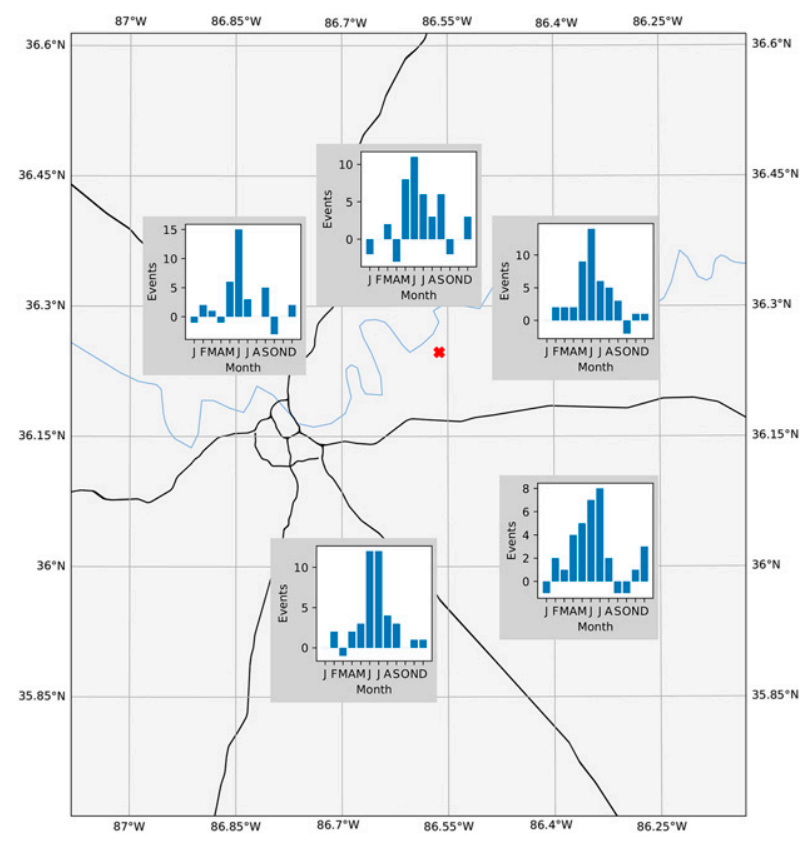

FIG. 11. As in Fig. 4, but for Nashville. The red $\mathrm{x}$ represents the KOHX radar.

across this season with patterns ranging from a stronger flow on the left side of the feature map and quiescent conditions on the right (Fig. 7a). In total, 131 urban and rural cases were classified from the summer months to nodes on the SOM (Fig. 7b). Cases were least likely to occur on the upper-left side of the SOM; these patterns have strong northwest flow aloft with the trough axis located to the east of Louisville. In these situations, subsidence is generally expected from quasigeostrophic theory because there is anticyclonic vorticity advection increasing with height. Cases occurred across the remainder of the SOM, with cases ranging from near-zonal flow (bottom center) to southwesterly flow (bottom right), to weak flow with various positions with respect to the thermal ridge (upper right). The speckled nature of case counts in the bottom of the SOM is more likely to be tied to sampling issues versus true neighboring class variability. Rather, we focus our attention to broad changes across the SOM (e.g., strong vs weak flow).

Urban and rural cases were separated to understand whether they have preferential $500 \mathrm{hPa}$ patterns of occurrence (Fig. 8). To limit issues with sampling, results are plotted as the fraction of total cases. While sampling cannot be completely negated (e.g., noise in fractions seen along the perimeter with urban cases), a clear shift in patterns can be seen. Overall, urban cases are more likely under quiescent conditions on the right-hand side of the SOM (Fig. 8a), while rural cases are more likely under synoptically active time periods (Fig. 8b).

\section{c. Other cities}

The results show that Louisville experiences significantly more days with isolated deep convective storms compared to nearby rural areas. However, a causal relationship for this has not been established. While it is likely that urban processes are responsible for this difference, it is also possible that other features-such as topographical variations-play a role. To further investigate this possibility, the procedure described in section $3 \mathrm{a}$ was repeated for Nashville, Tennessee, and Cincinnati, Ohio, with some modifications to the geometry of the focus/control areas (Fig. 9). For Nashville, the radial extent of the focus and control areas is 25 and $20 \mathrm{~km}$, respectively. For Cincinnati, the limits were 35 and $30 \mathrm{~km}$. Data from the KILN radar were used for Cincinnati and surrounding RPs, while KOHX radar data were used for Nashville and surrounding RPs. The range of possible radar beam heights for Nashville and surrounding RPs is approximately 100 to $500 \mathrm{~m}$ within the focus regions. For Cincinnati (and RPs), the lowest possible beam height ranges from 500 to $2000 \mathrm{~m}$. In addition to the five RPs identified around Cincinnati, a sixth location at $39.9697^{\circ}$ latitude and $-83.1691^{\circ}$ longitude was included (Fig. 9b). The focus area of this location extends over the Columbus metropolitan area (herein this point is referred to as CBS). The purpose of this location is to directly compare convective activity over two different urban areas, both of which are approximately the same distance from the same radar.

The total number of isolated convective events over Nashville is 175, and values over the RPs range from 132 to 146 (Table 2). Figure 10 shows the results from the permutation resampling and the $p$ values from this analysis are shown in Table 2. At four of the five RPs, the difference in isolated convective activity (relative to Nashville) is statistically significant at the $95 \%$ confidence level when significance was determined by the permutation method. RP2 ( $p$ value of 0.056) was the only comparison point where differences were not significant at the $95 \%$ confidence interval. When the Wilcoxon signed-rank test was used, a statistically significant difference in convective activity (at the 95\% confidence interval) was found at three of the RPs, with RP2 and RP4 being the locations that were not significantly different compared to Nashville. Differences in convective activity between the urban and rural environment tend to be maximized in June and July (Fig. 11), which is a narrower time frame than was found for Louisville, where peak differences relative to the various RPs occurred from May through August.

Cincinnati had 104 total events over the study period, which was the smallest of the three cities analyzed (Table 2). The total number of urban convective events over Cincinnati is greater than each of the five comparison RPs as well as the location over CBS. The results from the permutation resampling were statistically significant at the 95\% confidence interval (Fig. 12, Table 2) at four of the five RPs. As was the case with Nashville, the lone comparison RP that was not statistically significant (RP4; $p$ value of 0.054 ) was slightly outside the defined confidence interval. Interestingly, the CBS location yielded the most convective events of all of the comparison locations. Differences in convective activity between Cincinnati and CBS were not statistically significant, with $p$ values of 0.22 and 0.23 from the permutation testing and Wilcoxon methods. Figure 13 shows that differences in convective activity between Cincinnati and the RPs is maximized in July and August (Fig. 13), which is slightly later than the peak differences observed for Louisville and Nashville. 


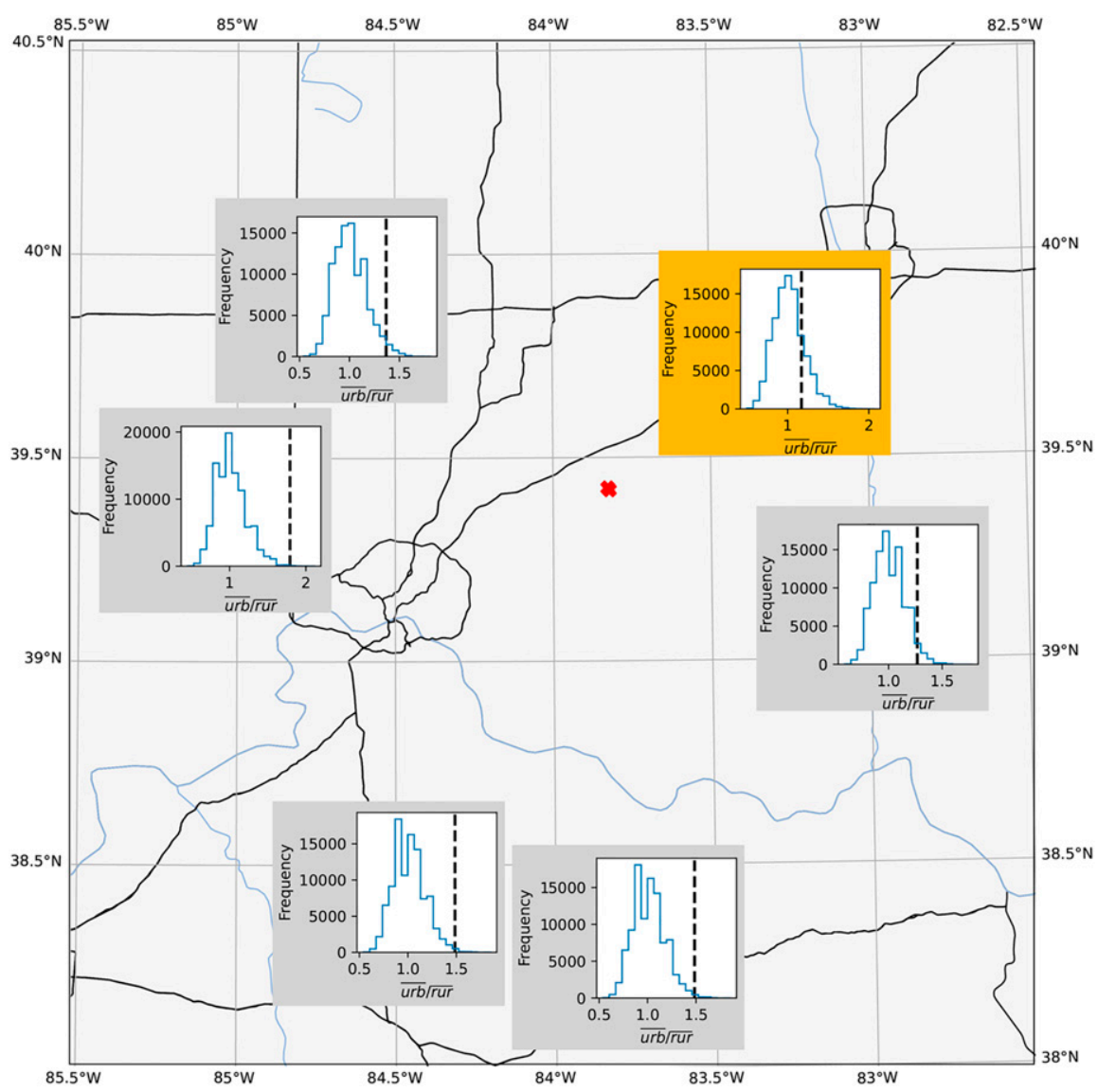

FIG. 12. As in Fig. 3, but for Cincinnati. The red $\mathrm{x}$ represents the KILN radar. The graph outlined in orange represents the comparison location overlapping Columbus.

\section{Discussion}

The results show that Louisville experiences strong, isolated convective activity more often than surrounding rural locations. This activity is more likely under quiescent conditions when there is weaker synoptic forcing. To determine if the results from Louisville were dominated by the impact of urban processes or may have been influenced by other local factors, the procedure was repeated for two nearby large cities-Nashville and Cincinnati. Indianapolis was also considered for analysis; however, the KIND radar is located only about $15 \mathrm{~km}$ from the downtown center of Indianapolis. This made it impossible to define RP focus regions that were approximately the same distance from the radar as the urban focus region and did not overlap with the urban focus region. This presents a limitation of our methodology - it cannot be used in cities where the nearest WSR-88D is very close to the city itself.

The results from the analysis of Nashville and Cincinnati also revealed greater convective activity in these cities compared to nearby rural areas, although each city had one RP where convective activity was not statistically different from that in the comparison urban area at the $95 \%$ confidence interval. Also, Cincinnati presented a unique opportunity since the KILN radar is nearly halfway between Cincinnati and Columbus. A sixth comparison site placed such that the focus area extended over the Columbus region. This location produced the smallest difference in convective activity (relative to Cincinnati) and the largest $p$ value of all tested points. This finding provides further evidence that convective initiation is enhanced over urban areas.

To examine the sensitivity of the results to the geometry of the control and focus areas, two additional experiments were completed for Louisville (not shown). In one test, the control and focus areas were rotated to be oriented from southwest to northeast-in better agreement with the mean summer wind direction and storm motion. ${ }^{2}$ This slightly changed the total number of events at each location but the urban-rural difference in convective activity remained statistically significant at each RP. In the second test, we removed the "gaps" between the control and focus area by increasing the size of the control area. This resulted in

\footnotetext{
${ }^{2}$ Wind climatology was determined using data from the Iowa Environmental Mesonet (https://mesonet.agron.iastate.edu/sites/ windrose.phtml?station $=$ LOU\&network $=$ KY_ASOS $)$.
} 


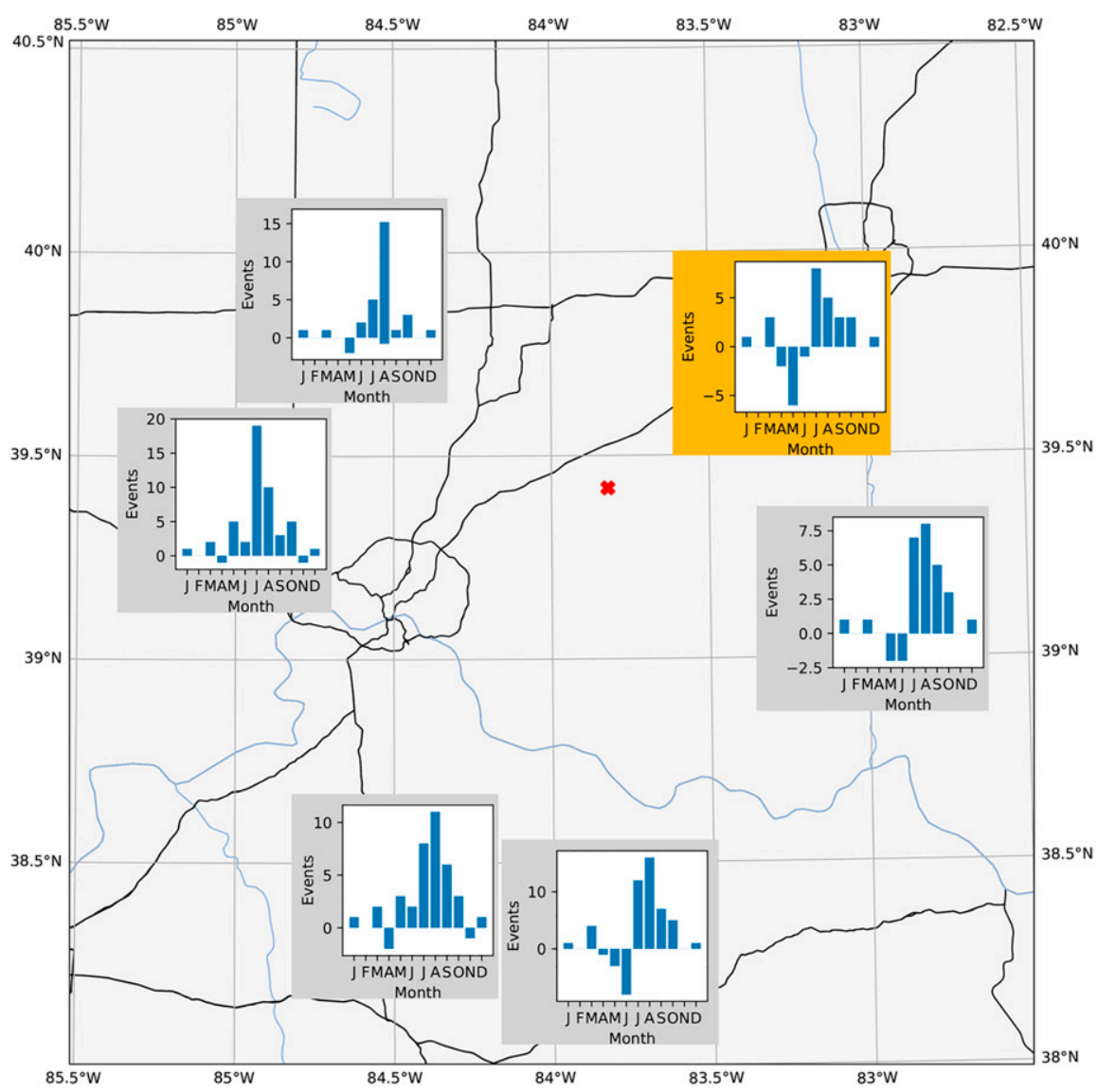

FIG. 13. As in Fig. 4, but for Cincinnati. The red $\mathrm{x}$ represents the KILN radar. The graph outlined in orange is the same as in Fig. 12.

substantially fewer events at each location do the more stringent criteria. For example, 71 isolated events were identified over Louisville using this method whereas our original method yielded 116 events (see Table 2). With this method, statistically significant differences in convective activity were found at four of the five RPs. Only RP1 did not produce a statistically significant result.

Since differences in urban-rural convective activity were strongest during the summer, the analysis was repeated considering only convective activity during the "warm" season, which we defined as May-September (not shown). This did not alter the significance of the results. For Louisville and Cincinnati, the number of RPs with significantly less convective activity remained the same. For Nashville, only three of the RPs yielded a statistically significant result when considering only the warm season, compared with four out of five when considering the full dataset.

While the findings of this study indicate that Louisville and the other cities tested experience more convective activity compared to nearby rural locations, none of the findings establish a physical mechanism for the increased convection or provide any assistance in predicting future convective events within the city. The University of
Louisville is currently in the process of deploying a network of surface-based weather stations around Louisville to study its UHI and other urban effects. The network is composed of Davis Vantage Pro2 stations located throughout the city. Observations from the partially completed network were examined to determine if a physical mechanism for convective initiation could be found and if urban-induced convective activity may be forecasted ahead of time. Figure 14 shows a surface analysis of eight stations within the network, as well as observations from the Automated Surface Observing System (ASOS) station at Bowman Field, from the afternoon of 10 July 2019. Note that this is the same date as the convective initiation event shown in Fig. 1. Figure 14a shows the surface conditions at 1800 UTC. The highest temperatures are located within the northeast corner of the city, and lower values are found in the south and southeast portions of Louisville. Winds are less than $5 \mathrm{kt}$ $\left(1 \mathrm{kt} \approx 0.5 \mathrm{~m} \mathrm{~s}^{-1}\right)$, with one of the stations in the eastern half of the city indicating westerly/southwesterly flow. By 1900 UTC (Fig. 14b), westerly winds increase in strength at locations in the northwest portion of the city. Farther to the east, the Bowman Field ASOS station reports winds from the southeast at $10 \mathrm{kt}$. To the south of Bowman Field, winds 
a.) $2019-07-1018: 00$ UTC

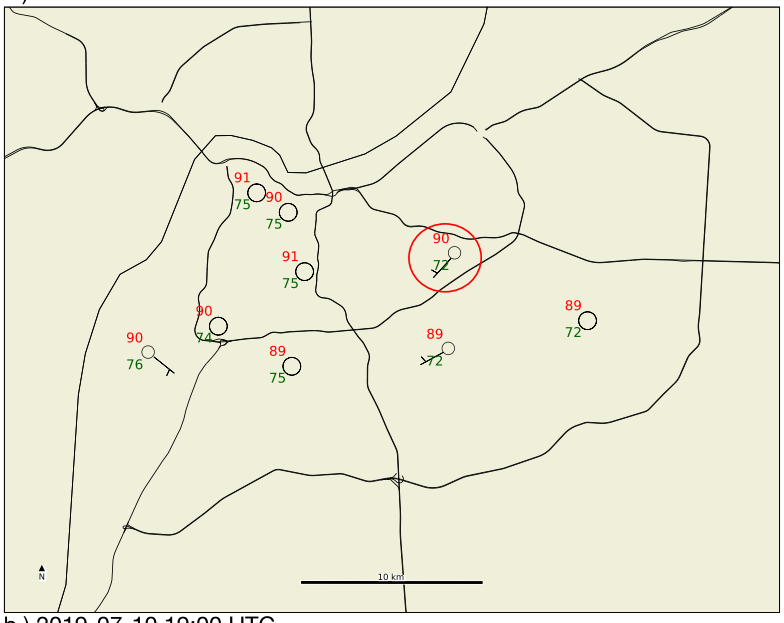

b.) 2019-07-10 19:00 UTC

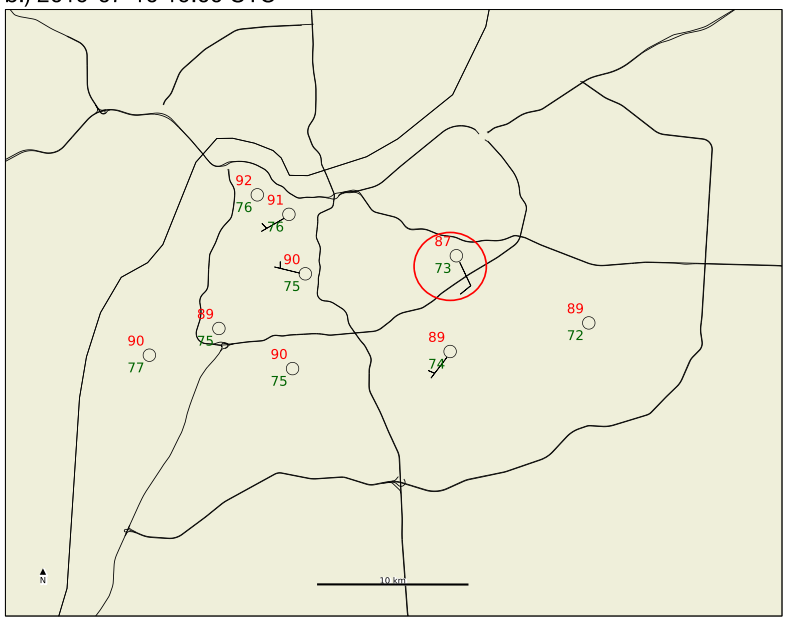

FIG. 14. Station plots from surface observation stations around Louisville from (a) 1800 and (b) 1900 UTC 10 Jul 2019. The Bowman Field station is circled in red. Wind observations at this station are taken at the standard $10-\mathrm{m}$ level, and wind measurements from the other stations are from approximately $3 \mathrm{~m}$ AGL.

are from the southwest. The shifting winds indicate a localized region of convergence near the center of Louisville. By 1917 UTC, reflectivity values of 30-40 dBZ begin to appear within this prospective region of convergence, and by 1917 UTC, reflectivity values of over $50 \mathrm{dBZ}$ are present (Fig. 1). This agrees with Bornstein and Lin (2000), who found evidence of near-surface convergence preceding urban initiated convection in Atlanta. While these initial results are promising, research involving the use of this observation network to anticipate convective development in real time is ongoing.

\section{Summary and conclusions}

This study investigated differences in the occurrence of strong, isolated convective cells between Louisville and five select nearby rural locations. Relative to five rural locations used for comparison, Louisville experienced significantly more strong isolated convective events over the period 200319. Differences in convective activity between Louisville and the surrounding rural areas are largest during meteorological summer, with a peak difference from May through August at most locations. Furthermore, it was found that relative to the rural locations, Louisville experiences more convective activity beginning in the afternoon and ending before midnight. Activity over the city is more likely during synoptically quiescent conditions. These findings agree with those of Haberlie et al. (2015) and their analysis of urban-induced convective initiation events in Atlanta. In contrast, the rural locations tend to experience more convection during the morning hours, and upper-level patterns suggested events were more likely tied to synoptic-scale forcing.

A similar analysis was completed for Nashville and Cincinnati. Each of these cities experienced more frequent convective activity over the study period than their five nearby rural locations. However, for both these cities differences in convective activity are statistically significant at four of the five rural locations. It was also found that the peak differences in convective activity, relative to the surrounding rural regions, occur in July-August for Cincinnati and June-July for Nashville.

Further research is needed to explore the physical mechanism(s) responsible for these observed differences. Based on the time of day and time of year that the differences are maximized, it is likely that the urban heat island plays a substantial role. However, it is possible that nonurban effects such as topography are impacting convective activity around these cities. Future work will focus on analyzing observations from the surfacebased network discussed in section 4 in combination with convective-allowing WRF simulations to explore these remaining questions.

Acknowledgments. A portion of this research was sponsored by the National Science Foundation, Grant AGS-1953791. Author Kennedy was supported by the National Science Foundation under NSF EPSCoR Track-1 Cooperative Agreement OIA 1355466. We thank the anonymous reviewers whose helpful comments and suggestions greatly improved an earlier version of this work.

\section{REFERENCES}

Ansari, S., M. Phillips, and S. Del Greco, 2009: NEXRAD severe weather signatures in the NOAA Severe Weather Data Inventory. 34th Conf. on Radar Meteorology, Williamsburg, VA, Amer. Meteor. Soc., P6.19, https://ams.confex.com/ams/ pdfpapers/156015.pdf.

Bentley, M. L., J. A. Stallins, and W. S. Ashley, 2012: Synoptic environments favourable for urban convection in Atlanta, Georgia. Int. J. Climatol., 32, 1287-1294, https://doi.org/10.1002/joc.2344.

Bornstein, R., and Q. Lin, 2000: Urban heat islands and summertime convective thunderstorms in Atlanta: Three case studies. Atmos. Environ., 34, 507-516, https://doi.org/10.1016/S13522310(99)00374-X. 
Braham, R. R., R. G. Semonin, A. H. Auer, and S. A. Changnon, 1981: Summary of urban effects on cloud and rain. METROMEX: A Review and Summary, Meteor. Monogr., No. 40, Amer. Meteor. Soc., 141-152.

Changnon, S. A., F. A. Huff, and R. G. Semonin, 1971: METROMEX: An investigation of inadvertent weather modification. Bull. Amer. Meteor. Soc., 52, 958-968, https://doi.org/10.1175/15200477(1971)052<0958:MAIOIW > 2.0.CO;2.

,-- P. T. Schickedanz, and J. L. Vogel, 1977: Weather Anomalies and Impacts. Vol. 1, Summary of METROMEX, Illinois State Water Survey Bull. 62, 260 pp., https://www. isws.illinois.edu/pubdoc/B/ISWSB-62.pdf.

Craig, K. J., and R. D. Bornstein, 2002: MM5 simulations of urban induced convective precipitation over Atlanta. Fourth Symp. on the Urban Environment, Norfolk, VA, Amer. Meteor. Soc., 1.3, https://ams.confex.com/ams/AFMAPUE/techprogram/ paper_38803.htm.

Debbage, N., and J. M. Shepherd, 2015: The urban heat island effect and city contiguity. Comput. Environ. Urban Syst., 54, 181-194, https://doi.org/10.1016/j.compenvurbsys.2015.08.002.

Dixon, P. G., and T. L. Mote, 2003: Patterns and causes of Atlanta's urban heat island-initiated precipitation. J. Appl. Meteor., 42, 1273-1284, https://doi.org/10.1175/1520-0450(2003)042<1273: PACOAU $>2.0 . \mathrm{CO} ; 2$.

Ganeshan, M., R. Murtugudde, and M. L. Imhoff, 2013: A multicity analysis of the UHI-influence on warm season rainfall. Urban Climate, 6, 1-23, https://doi.org/10.1016/j.uclim.2013.09.004.

Haberlie, A. M., W. S. Ashley, and T. J. Pingel, 2015: The effect of urbanisation on the climatology of thunderstorm initiation. Quart. J. Roy. Meteor. Soc., 141, 663-675, https://doi.org/ 10.1002/qj.2499.

Hjelmfelt, M. R., 1982: Numerical simulation of the effects of St. Louis on mesoscale boundary-layer airflow and vertical air motion: Simulations of urban vs non-urban effects. J. Appl. Meteor., 21, 1239-1257, https://doi.org/10.1175/1520-0450(1982) 021<1239:NSOTEO $>2.0 . \mathrm{CO} ; 2$.

Huff, F. A., and S. A. Changnon, 1973: Precipitation modification by major urban areas. Bull. Amer. Meteor. Soc., 54, 1220-1232, https://doi.org/10.1175/1520-0477(1973)054<1220:PMBMUA> 2.0.CO;2.

Jin, M., J. M. Shepherd, and M. D. King, 2005: Urban aerosols and their variations with clouds and rainfall: A case study for New York and Houston. J. Geophys. Res., 110, D10S20, https:// doi.org/10.1029/2004JD005081.

Kennedy, A. D., X. Dong, and B. Xi, 2016: Cloud fraction at the ARM SGP site: Reducing uncertainty with self-organizing maps. Theor. Appl. Climatol., 124, 43-54, https://doi.org/ 10.1007/s00704-015-1384-3.

_ - A. Trellinger, T. Grafenauer, and G. Gust, 2019: A climatology of atmospheric patterns associated with Red River valley blizzards. Climate, 7, 66, https://doi.org/10.3390/cli7050066.

Kohonen, T., 1989: Self-Organization and Associative Memory. 3rd ed. Springer-Verlag, $312 \mathrm{pp}$.

Liu, J., and D. Niyogi, 2019: Meta-analysis of urbanization impact on rainfall modification. Sci. Rep., 9, 7301, https://doi.org/ 10.1038/s41598-019-42494-2.

McLeod, J., M. Shepherd, and C. E. Konrad, 2017: Spatio-temporal rainfall patterns around Atlanta, Georgia and possible relationships to urban land cover. Urban Climate, 21, 27-42, https://doi.org/10.1016/j.uclim.2017.03.004.

Mecikalski, J. R., and K. M. Bedka, 2006: Forecasting convective initiation by monitoring the evolution of moving cumulus in daytime GOES imagery. Mon. Wea. Rev., 134, 49-78, https:// doi.org/10.1175/MWR3062.1.

Mesinger, F., and Coauthors, 2006: North American Regional Reanalysis. Bull. Amer. Meteor. Soc., 87, 343-360, https:// doi.org/10.1175/BAMS-87-3-343.

Mote, T. L., M. C. Lacke, and J. M. Shepherd, 2007: Radar signatures of the urban effect on precipitation distribution: A case study for Atlanta, Georgia. Geophys. Res. Lett., 34, L20710, https://doi.org/10.1029/2007GL031903.

Naylor, J., and A. Sexton, 2018: The relationship between severe weather warnings, storm reports, and storm cell frequency in and around several large metropolitan areas. Wea. Forecasting, 33, 1339-1358, https://doi.org/10.1175/WAF-D-18-0019.1.

Niyogi, D., P. Pyle, M. Lei, S. P. Arya, C. M. Kishtawal, M. Shepherd, F. Chen, and B. Wolfe, 2011: Urban modification of thunderstorms: An observational storm climatology and model case study for the Indianapolis urban region. J. Appl. Meteor. Climatol., 50, 1129-1144, https://doi.org/ 10.1175/2010JAMC1836.1.

Ochoa, C. A., A. I. Quintanar, G. B. Raga, and D. Baumgardner, 2015: Changes in intense precipitation events in Mexico City. J. Hydrometeor., 16, 1804-1820, https://doi.org/10.1175/JHMD-14-0081.1.

Reames, L. J., and D. J. Stensrud, 2018: Influence of a Great Plains urban environment on a simulated supercell. Mon. Wea. Rev., 146, 1437-1462, https://doi.org/10.1175/MWR-D-17-0284.1.

Rozoff, C. M., W. R. Cotton, and J. O. Adegoke, 2003: Simulation of St. Louis, Missouri, land use impacts on thunderstorms. J. Appl. Meteor., 42, 716-738, https://doi.org/10.1175/15200450(2003)042<0716:SOSLML > 2.0.CO;2.

Shem, W., and M. Shepherd, 2009: On the impact of urbanization on summertime thunderstorms in Atlanta: Two numerical model case studies. Atmos. Res., 92, 172-189, https://doi.org/ 10.1016/j.atmosres.2008.09.013.

Shepherd, J. M., and S. J. Burian, 2003: Detection of urban-induced rainfall anomalies in a major coastal city. Earth Interact., 7, https://doi.org/10.1175/1087-3562(2003)007<0001:DOUIRA> 2.0.CO;2.

— H. Pierce, and A. J. Negri, 2002: Rainfall modification by major urban areas: Observations from spaceborne rain radar on the TRMM satellite. J. Appl. Meteor., 41, 689-701, https:// doi.org/10.1175/1520-0450(2002)041<0689:RMBMUA>2.0.CO;2.

Stallins, J. A., J. Carpenter, M. L. Bentley, W. S. Ashley, and J. A. Mulholland, 2013: Weekend-weekday aerosols and geographic variability in cloud-to-ground lightning for the urban region of Atlanta, Georgia, USA. Reg. Environ. Change, 13, 137-151, https://doi.org/10.1007/s10113-012-0327-0.

Thielen, J., W. Wobrock, A. Gadian, P. G. Mestayer, and J. D. Creutin, 2000: The possible influence of urban surfaces on rainfall development: A sensitivity study in $2 \mathrm{D}$ in the meso$\gamma$-scale. Atmos. Res., 54, 15-39, https://doi.org/10.1016/S01698095(00)00041-7.

van den Heever, S. C., and W. R. Cotton, 2007: Urban aerosol impacts on downwind convective storms. J. Appl. Meteor. Climatol., 46, 828-850, https://doi.org/10.1175/JAM2492.1.

Wang, J., X. Dong, A. Kennedy, B. Hagenhoff, and B. Xi, 2019: A regime-based evaluation of southern and northern Great Plains warm-season precipitation events in WRF. Wea. Forecasting, 34, 805-831, https://doi.org/10.1175/WAF-D-19-0025.1.

Wilcoxon, F., 1945: Individual comparisons by ranking methods. Biom. Bull., 1, 80-83, https://doi.org/10.2307/3001968.

Wilks, D. S., 2006: Statistical Methods in the Atmospheric Sciences. 2nd ed. Elsevier, 627 pp. 